\title{
Characteristics of the allotropic phase transformation in titanium processed by high-pressure torsion using different rotation speeds
}

\author{
Hamed Shahmir ${ }^{\mathrm{a}, *}$, Terence G. Langdon ${ }^{\mathrm{a}, \mathrm{b}}$ \\ ${ }^{a}$ Materials Research Group, Faculty of Engineering and the Environment, \\ University of Southampton, Southampton SO17 1BJ, UK \\ ${ }^{b}$ Departments of Aerospace \& Mechanical Engineering and Materials Science, \\ University of Southern California, Los Angeles, CA 90089-1453, USA
}

\begin{abstract}
An investigation was initiated to examine the effect of rotation speed on the allotropic $\alpha$ to $\omega$-phase transformation in titanium. A grade 2 commercial purity titanium was processed by high-pressure torsion (HPT) at room temperature up to a maximum of 10 turns using a pressure of $5.0 \mathrm{GPa}$ and different rotation speeds from 0.5 to $2 \mathrm{rpm}$. It is shown that the allotropic phase transformation occurs during HPT at different rotation speeds but the volume fraction of the $\omega$-phase decreases when the rotation speed is increased. The results indicate that the hardness and strength are decreased by processing the specimens at higher rotation speeds. Additional annealing for $15 \mathrm{~min}$ at 423 and $473 \mathrm{~K}$ after HPT processing is also effective in changing the volume fractions of the $\omega$-phase and producing an $\omega$ to $\alpha$ reverse phase transformation. The results are interpreted in terms of the temperature rise during HPT processing.
\end{abstract}

Keywords: high-pressure torsion; nanostructured materials; phase transformations; severe plastic deformation; titanium;

*Corresponding author. Tel.: +442380594438

E-mail address: H.Shahmir@soton.ac.uk 


\section{Introduction}

It is well known that titanium (Ti) displays three phases depending on the pressure and temperature. The hexagonal close-packed $\alpha$-phase is stable at ambient temperature and pressure but this phase transforms to the body-centered cubic $\beta$-phase at temperatures above $1155 \mathrm{~K}$ under ambient pressure [1]. The existence of the $\beta$-phase was also predicted theoretically at pressures higher than $\sim 36 \mathrm{GPa}$ but this transformation was never observed experimentally $[2,3]$. An $\alpha$ to $\omega$ martensitic phase transformation occurs under high pressures at ambient temperature [1] where the crystal structure of the $\omega$-phase is composed of a regular hexagonal close-packed lattice but with an open structure having only 3 atoms per unit cell at $(0,0,0),(1 / 2,2 / 3, c / 2 a)$, and $(2 / 3,1 / 3, c / 2 a)$ where $a$ and $c$ are the lattice parameters in the basal plane and perpendicular to the basal plane, respectively, and the axial ratio is $c / a \approx 0.62[4]$.

The high-pressure $\omega$-phase exhibits a reverse phase transformation upon heating or when the pressure is reduced [5]. It is now well established that straining using high-pressure torsion (HPT) may produce a stabilization of the high-pressure $\omega$-phase under ambient conditions [6-11]. Furthermore, the $\omega$-phase is harder than the $\alpha$-phase so that the $\alpha$ to $\omega$ phase transformation during HPT processing produces extra hardening and strengthening of the pure Ti. In practice, it appears that HPT may be the only technique that is easily available for introducing a high volume fraction of the $\omega$-phase in pure Ti [12].

Processing by HPT is now a well-established procedure for obtaining nanometer and submicrometer microstructures in bulk solids $[13,14]$. In processing by HPT, a disk-shaped specimen is deformed by simple shear between two anvils where it is constrained under a high pressure and subjected to concurrent torsional straining [15]. The applied pressure is an important factor in initiating the $\alpha$ to $\omega$-phase transformation since it is necessary to apply a 
pressure greater than a critical value of $\sim 2 \mathrm{GPa}$ in order to produce this transformation: thus, an earlier report demonstrated that the fraction of the $\omega$-phase increased both with increasing pressure from 3 to $6 \mathrm{GPa}$ and with increasing shear strain [6]. In practice, it appears that this straining facilitates, but does not initiate, the phase transformation [9] so that a large shear strain is insufficient to produce a phase transformation in the absence of a high hydrostatic pressure [16].

The effects on the phase transformation of the processing temperature and initial grain size were investigated recently [10]. Initially, it was expected that decreasing the processing temperature may promote the formation of the $\omega$-phase but, on the contrary, experiments showed that the fraction of the $\omega$-phase decreased when the processing temperature was decreased from room temperature to cryogenic temperatures and this was related to the formation of smaller nanometer grain sizes when processing by HPT at cryogenic temperatures [10]. Thus, the $\omega$-phase volume fraction decreased with decreasing average grain size and the $\omega$-phase was absent when the average grain size was $\sim 20 \mathrm{~nm}[10]$. Another important parameter in the $\alpha$ to $\omega$ transformation is the role of any impurities in Ti. There is evidence that the presence of oxygen suppresses the $\alpha$ to $\omega$-phase transformation because oxygen increases both the $\omega$-phase energy relative to the $\alpha$-phase and the energy barrier for the transformation [17]. As a consequence, the $\omega$-phase was not detected in commercial purity Ti containing a relatively high oxygen content even after processing at $6.0 \mathrm{GPa}$ [18].

Although numerous reports document the effects of impurities and processing parameters, such as pressure, numbers of rotations and processing temperature, on the occurrence of the $\alpha$ to $\omega$-phase transformation in HPT, only very limited information is at present available on the effect of strain rate, and thus anvil rotation speed, on the nature of the phase transformation. Furthermore, most reports have focused on samples deformed at a conventional rotation speed of $1 \mathrm{rpm}[8,10,16,18]$. There is only a single report showing that 
the strain rate has little significance on the $\alpha$ to $\omega$-phase transformation when using rotation speeds of 0.2 and $0.5 \mathrm{rpm}$ [9]. Accordingly, the present investigation was initiated to address this deficiency by examining the effect of different HPT rotation speeds on the $\alpha$ to $\omega$-phase transformation, the microstructural evolution and the mechanical properties of the processed material. As will be demonstrated, the results show that the rotation speed has a critical effect on the magnitude of the transformation and especially on the total volume fraction of the $\omega$ phase.

\section{Experimental material and procedures}

The experiments were conducted on commercial purity (CP) grade 2 titanium $(99.2 \%$ purity) that was annealed for $2 \mathrm{hr}$ at $972 \mathrm{~K}$ under an Ar-controlled atmosphere to give an $\alpha$ phase microstructure with an average grain size of $\sim 65 \mu \mathrm{m}$. Titanium disks with thicknesses of $\sim 0.8 \mathrm{~mm}$ and diameters of $10 \mathrm{~mm}$ were processed by HPT at room temperature under an applied pressure of $P=5.0 \mathrm{GPa}$ using rotation speeds of $0.5,1$ and $2 \mathrm{rpm}$ and rotations through totals of 1,5 and 10 revolutions under quasi-constrained conditions $[19,20]$. A K-

type (chromel-alumel) thermocouple was inserted in a hole at the back of the upper anvil and this was used to record the temperature of the upper anvil at a position $\sim 10 \mathrm{~mm}$ from the HPT sample by making a small vertical hole in the centre of the upper anvil as described in an earlier report [21].

After HPT, some samples processed for 10 turns at $0.5 \mathrm{rpm}$ rotation speed were annealed at temperatures of 423 or $473 \mathrm{~K}$ for 15 min under an Ar-controlled atmosphere. Each HPT disk, both after HPT processing and after HPT processing and annealing, was polished to a mirror-like quality and hardness measurements were taken using a Vickers microhardness tester with a load of 500 gf and dwell times of $10 \mathrm{~s}$. The average microhardness values, Hv, were measured along randomly selected diameters on each disk with the measurements taken 
at intervals of $\sim 0.5 \mathrm{~mm}$ and at every point the local value of $\mathrm{Hv}$ was obtained from an average of four separate hardness measurements. The transformation temperatures were measured by differential scanning calorimetery (DSC) using a Mettler-Toledo instrument with the analysis performed using non-isothermal (scanning) experiments upon heating at a scanning rate of $\sim 10 \mathrm{~K} \mathrm{~min}^{-1}$ and covering a temperature range of $298-773 \mathrm{~K}$. The phase constituents were determined using X-ray diffraction (XRD) (Rigaku SmartLab) employing $\mathrm{Cu} \mathrm{K} \alpha$ radiation (wavelength $\lambda=0.154 \mathrm{~nm}$ ) at $45 \mathrm{kV}$ and a tube current of $200 \mathrm{~mA}$. The XRD measurements were performed over a $2 \theta$ range from $30^{\circ}$ to $90^{\circ}$ using a scanning step of $0.01^{\circ}$ and a scanning speed of $2^{\circ} \mathrm{min}^{-1}$. The analyses using DSC and XRD were conducted using sample areas with diameters of $3 \mathrm{~mm}$ located near the edges of the disks. A foil for transmission electron microscopy (TEM) was prepared using a focused ion beam (FIB) (Zeiss Nvision $40 \mathrm{FIB}$ ) method at $3 \mathrm{~mm}$ from the disk centre in the normal section of the disk so that the normal of the image lay in the shear direction. The TEM micrographs were obtained using a JEOL JEM-3010 microscope operating under an accelerating voltage of $300 \mathrm{kV}$.

Miniature tensile specimens were cut from near the edges of the HPT disks with gauge dimensions of $1.1 \times 1.0 \times 0.6 \mathrm{~mm}^{3}$ and the stress-strain curves were recorded under conditions of constant rate of cross-head displacement at room temperature using an initial strain rate of $1.0 \times 10^{-3} \mathrm{~s}^{-1}$ with a Zwick universal testing machine. The stress-strain curves were plotted for each specimen to give the yield stress and ultimate tensile strength. Two samples were tested for each condition. The elongations were estimated by carefully measuring the gauge lengths before and after tensile testing using an optical microscope.

\section{Experimental results}

\subsection{Microstructure and hardness after HPT processing}

Figure 1(a) shows the X-ray diffraction patterns at the edges of the disks of the CP-Ti 
after HPT processing for different rotation speeds, $w$, at $N=10$. Earlier results in a fullyannealed condition without HPT processing showed that, as anticipated, the initial microstructure consisted only of the $\alpha$-phase Ti with a main peak of (10-10) $\alpha$. Inspection of the X-ray patterns demonstrates that $\omega$-phase peaks are clearly visible in Fig. 1(a) with the main peak position corresponding to the $(11-20)_{\omega}$ planes at $2 \theta \approx 39^{\circ}$ thereby confirming the occurrence of the $\alpha$ to $\omega$-phase transformation. The results indicate that the intensities of the $\omega$-phase peaks decrease with increasing rotation speed such that the intensities of these peaks are essentially negligible when using the fastest rotation rate of $2 \mathrm{rpm}$. The volume fractions of the $\omega$-phase after HPT processing were calculated using standard procedures [22] and the results are shown in the last column of Table 1. Estimates of the $\omega$-phase volume fractions based on the XRD results are summarized in Table 1 and show changes from $\sim 65 \%$ for 0.5 rpm to $\sim 27 \%$ and $\sim 12 \%$ at rotation speeds of 1 and $2 \mathrm{rpm}$, respectively.

The results for the corresponding Vickers microhardness measurements are shown in Fig. 1(b) for the same number of 10 rotations after processing through different rotation speeds with the average values of Hv plotted along each disk diameter and with the lower dashed line at $\mathrm{Hv} \approx 170$ corresponding to the initial hardness in the fully-annealed condition. The microhardness results in Fig. 1(b) show that the hardness decreases significantly with increasing rotation speed. Thus, the hardness values at the edges of the disks after 10 turns decrease from $\mathrm{Hv} \approx 370$ to $\sim 304$ and $\sim 294$ when the rotation rate increases from 0.5 to 1 and 2 rpm, respectively. These hardness measurements are consistent with the measured equilibrium volume fractions of the $\omega$-phase since this phase is harder than the $\alpha$-phase [1].

The microstructure and an appropriate selected area electron diffraction (SAED) pattern are shown in Fig. 2 at a region $\sim 3 \mathrm{~mm}$ from disk centre after HPT through 10 turns at $0.5 \mathrm{rpm}$. This microstructure consists of an array of ultrafine equiaxed grains having an average size of $\sim 70 \mathrm{~nm}$. This is typical of materials prepared using severe plastic deformation (SPD) 
techniques and it is consistent with the presence of a large volume of high-energy nonequilibrium boundaries $[23,24]$. Strain contrast is visible in many of these small grains which is associated with the presence of dislocations. In addition, the arrangement of the diffraction spots in semi-continuous circles in the SAED pattern confirms that the microstructure contains boundaries having high angles of misorientation. Analysis of the SAED pattern clearly shows the existence of $\omega$ and $\alpha$ phases in the microstructure which is consistent with the XRD result.

The effect of the numbers of rotations at a rotation speed of $0.5 \mathrm{rpm}$ is shown in Fig. 3 for (a) the XRD patterns at the edges of the disks and (b) the hardness measurements across the disk diameters. The XRD patterns reveal that $(0002)_{\alpha}$ becomes dominant after the first revolution and $\omega$-phase peaks are clearly visible in Fig. 3(a) even after processing through only 1 turn. Furthermore, the patterns in Fig. 3(a) illustrate the effect of the numbers of rotations on the $\alpha$ to $\omega$-phase transformation since it is apparent that the intensities of the $\omega$ phase peaks increase with increasing numbers of revolutions. Close inspection of these results indicates that the intensity of $(11-20)_{\omega}$ increases at the expense of the intensity of $(0002)_{\alpha}$. The volume fractions of the $\omega$-phase after HPT processing are shown in the last column of Table 1 where it is apparent that, at a rotation speed of $0.5 \mathrm{rpm}$, the $\omega$-phase volume fraction increases from $\sim 5$ to $\sim 65 \%$ when the numbers of rotations are increased from 1 to 10 turns.

The results for the corresponding Vickers microhardness measurements are shown in Fig. 3(b) for the same rotation speed of $0.5 \mathrm{rpm}$ after processing through different numbers of turns with the average values of Hv plotted along each disk diameter. Inspection of Fig. 3(b) shows that, with reference to the annealed condition, the hardness at the edge of the disk increases by a factor of $\sim 1.8$ to $\mathrm{Hv} \approx 306$ after 1 turn whereas the hardness in the centre increases only from $\mathrm{Hv} \approx 170$ to $\mathrm{Hv} \approx 228$. At the edges of the disks the hardness values 
increase with further straining to $\sim 350$ and $\sim 368$ after 5 and 10 turns, respectively, and in the centres the hardness values also gradually increase to $\mathrm{Hv} \approx 301$ after 10 turns. These results confirm the gradual evolution in hardness with increasing torsional straining. Earlier studies on different materials demonstrated that there is a good correlation between the values recorded in microhardness measurements and the internal microstructures [25-27]. The average values of hardness and the associated error bars are shown in the third column of Table 1.

\subsection{Tensile stress-strain behavior}

Representative plots of engineering stress against engineering strain are shown in Fig. 4(a) for the annealed condition and samples of CP-Ti after 10 turns using different rotation speeds. Inspection of these curves shows that, as expected, HPT processing produces a significant increase in strength of the CP-Ti but with a corresponding decrease in the measured elongations to failure. This is consistent with the classical mechanical behavior of ultrafine-grained metals that are tested in tension at relatively low temperatures after processing using SPD techniques $[28,29]$. The results show that the strength decreases with increasing rotation speed but the elongations to failure increase with increasing speed. These results are fully consistent with the hardness data documented for these samples in Fig. 1(b). All results for the different experimental conditions are summarized in Table 1.

The mechanical properties of samples of CP-Ti for the annealed condition (designated $N$ $=0$ ) and samples processed through 1, 5 and 10 turns at a rotational speed of $0.5 \mathrm{rpm}$ are illustrated in Fig. 4(b). The ultimate tensile strength (UTS) increases and the elongation to failure, $\delta$, decreases with increasing numbers of turns and for the sample processed through $N$ $=10$ turns the UTS is $\sim 1 \mathrm{GPa}$ and the elongation to failure is only $\sim 3 \%$ as summarized in Table 1.

\subsection{Thermal stability of the $\omega$-phase}


Non-isothermal DSC measurements were undertaken on disks processed through 10 turns at a rotation speed of $0.5 \mathrm{rpm}$ in order to qualitatively examine the thermal stability of the $\omega$-phase. The result is shown in Fig. 5 and indicates the appearance of two exothermic peaks on the first run after HPT processing. However, the peaks disappear during heating of the sample in the second run. According to the XRD results in Fig. 1(a), the microstructure of the CP Ti after HPT processing contains both $\alpha$ and $\omega$-phases. Therefore, the peaks in Fig. 5 are related to the occurrence of an $\omega$ to $\alpha$ reverse transformation during heating and the occurrence of two peaks is probably associated with the material heterogeneity which is an inherent feature of processing by HPT. The result in Fig. 5 shows that the $\omega$ to $\alpha$ reverse phase transformation occurs in the temperature range of $377-470 \mathrm{~K}$ which is consistent with earlier published data $[7,10]$.

To more clearly clarify the microstructural effect of an $\omega$ to $\alpha$ reverse phase transformation, XRD and microhardness measurements were performed on the samples processed through 10 turns of HPT at $0.5 \mathrm{rpm}$ and then annealed for $15 \mathrm{~min}$ at 423 or $473 \mathrm{~K}$. As shown in Fig. 6(a), the intensity of the $\omega$-phase peaks decrease significantly after annealing at $423 \mathrm{~K}$ for $15 \mathrm{~min}$ and the $\omega$-phase peaks are almost entirely absent after annealing for $15 \mathrm{~min}$ at the higher temperature of $473 \mathrm{~K}$. These results demonstrate conclusively that the $\omega$ to $\alpha$ reverse phase transformation occurs at $473 \mathrm{~K}$ which is consistent with the DSC results in Fig. 5. As shown by the hardness measurements in Fig. 6(b), the microhardness of the sample is reduced to $\mathrm{Hv} \approx 282$ after annealing at $473 \mathrm{~K}$ due to the reverse transformation and the consequent relaxation of the severely deformed material. According to earlier experiments [30], there is evidence for a significant decrease in lattice distortions without any visible grain growth after short-term annealing at such a low annealing temperature ( 323 and $373 \mathrm{~K}$ for $10 \mathrm{~min}$ ). In this condition, the grain size remains unchanged but the grain boundaries become better defined with more uniform contrast [30]. 
Therefore, it is expected that the hardness decreased due to the occurrence of a reverse phase transformation. Furthermore, it is apparent from Fig. 6(b) that this lower value of the Vickers microhardness remains constant throughout the disk after annealing at $473 \mathrm{~K}$.

\subsection{Temperature increment during HPT}

The temperatures were recorded experimentally after 10 turns for the three different rotation rates of $0.5,1$ and $2 \mathrm{rpm}$ and the results are plotted in Fig. 7. These measurements were recorded at the central position relative to the disk so that the radius was $r=0 \mathrm{~mm}$ but at a height perpendicular to the disks, $z$, given by $z=10 \mathrm{~mm}$. Inspection of Fig. 7 shows that, for rotation at a rate of $0.5 \mathrm{rpm}$, the temperature increases significantly in the very early stages of processing but levels off and reaches an essentially steady-state condition after about 5 min. This steady-state is due to the development of a reasonable balance between the rate of heat generation in the sample and the rate of cooling to the anvils. Neverthless, the temperature increases with increasing speed of rotation such that the anvil temperatures may reach $\sim 305, \sim 313$ and $\sim 321 \mathrm{~K}$ after 10 turns of processing with rates of $0.5,1$ and $2 \mathrm{rpm}$, respectively. It is important to note that these temperatures relate to the temperatures in the anvils connected to the disks and the values were recorded at a distance of $10 \mathrm{~mm}$ from the disk surfaces. This means in practice that the true temperatures of the disks are higher than these measured values.

\section{Discussion}

\subsection{General characteristics of the allotropic phase transformation}

The results from this investigation provide a clear demonstration that an $\alpha$ to $\omega$-phase transformation occurs during HPT processing. The XRD results presented in Fig. 3(a) indicate a strong deformatiom texture in HPT-processed samples. The (0002) $)_{\alpha}$ peak is dominant at the beginning of the process and by straining the intensity of (11-20) $)_{\omega}$ increases 
at the expense of the intensity of (0002) $\alpha$. The $\alpha$ to $\omega$ transformation occurs as a result of atomic shuffles in the $(0001)_{\alpha}$ planes and leads to the formation of the (11-20) $)_{\omega}$ planes $[8,31]$. Accordingly, the orientation relationship between the $\alpha$ and HPT-induced $\omega$ is given by $(0001)_{\alpha}\left\|(11-20)_{\omega} ;[11-20]_{\alpha}\right\|[0001]_{\omega}[8,31]$.

It is important to note that, in contrast to the significant role of the $(0002)_{\alpha}$ planes in the forward phase transformation, no $(0002)_{\alpha}$ is detected in the reverse transformation. This is in good agreement with earlier research suggesting that the the mechanisms of forward and reverse transformations are different [10,31]. The forward phase transformation is a diffusionless phase transformation while the reverse transformation formed by the HPT process is diffusion-controlled [10,31].

These results cleary demonstrate that the volume fraction of the $\omega$-phase decreases with increasing rotation speed in Fig. 1(a) and increases with increasing straining in Fig. 3(a). Furthermore, this phase transformation significantly affects the mechanical properties of the CP-Ti because the $\alpha$ to $\omega$-phase transformation leads to a very significant increase in both hardness and strength. Thus, the hardness and strength decrease with increasing rotation rate up to 10 turns due to the reduced volume fraction of the $\omega$-phase. This is consistent with earlier studies showing that pressure and straining are two important parameters in initiating the phase transformation and in practice there are critical values for the applied pressure and numbers of rotations for the onset of the phase transformation [6-10].

Based on microstructural evolutions during HPT processing and after annealing as investigated by XRD, it appears that the smaller amount of $\omega$-phase at higher rotation speeds is due to a prevention of $\omega$-phase formation rather than to the reverse $\omega$ to $\alpha$ transformation during HPT. It is reasonable to anticipate that heat generation during HPT processing is the main contributor preventing the formation of the $\omega$-phase at higher rotation speeds. It is important to note also that the difficulty in $\omega$-phase formation is assisted by the low stability 
of the $\omega$-phase and the occurrence of the $\omega$ to $\alpha$ reverse phase transformation at relatively low temperatures $(377-470 \mathrm{~K})$. Thus, the annealing and XRD results in Fig. 6(a) confirm that the $\omega$ to $\alpha$ reverse phase transformation begins to occur at temperatures at least as low as $\sim 423 \mathrm{~K}$.

\subsection{The effect of temperature rise in HPT processing}

A general relationship for the temperature rise, $\Delta T$, during plastic deformation is given in the form [32]:

$$
\Delta T \approx \frac{0.9}{\rho C_{\mathbf{P}}} \int \sigma d \varepsilon
$$

where $\rho$ is the density of the material, $C_{\mathrm{p}}$ is the specific heat capacity, $\sigma$ is the flow stress, $\varepsilon$ is the plastic deformation and the fraction of plastic deformation converted into heat is assumed to be $\sim 0.9$. In practice, the flow curve of CP-Ti in the fully-annealed condition, as shown in Fig. 4, may be approximately estimated from a Hollomon-type equation of the form $\sigma \approx 670$ $\operatorname{MPa} \varepsilon^{0.2}$ so that the amount of plastic work imposed on the material is calculated as $\int \sigma d \varepsilon \approx$ $134 \varepsilon^{1.2} \mathrm{MJ} \mathrm{m}^{-3}$. Taking the density and specific heat of CP-Ti as $4.43 \times 10^{6} \mathrm{~g} \mathrm{~m}^{-3}$ and $0.52 \mathrm{~J}$ $\mathrm{g}^{-1} \mathrm{~K}^{-1}$, respectively, the temperature increment from eq. (1) is estimated as $\Delta T \approx 309 \varepsilon^{1.2} \mathrm{~K}$ so that, taking $\varepsilon \approx 0.6$, it follows that $\Delta T \approx 165 \mathrm{~K}$. Therefore, for a specimen deformed at room temperature $(296 \mathrm{~K})$, it appears that the temperature may increase to a value of $\sim 460 \mathrm{~K}$. This is consistent with other calculations of temperature rises in HPT processing $[33,34]$ and the rise is sufficient to prevent the $\alpha$ to $\omega$-phase transformation. Nevertheless, the calculation is not adequate because it assumes adiabatic conditions with no heat loss from the sample to the massive HPT anvils. To evaluate this alternative approach, it is first necessary to examine the temperature rise measured experimentally within the anvils.

The temperature increment after 10 turns for the three different rotation rates of $0.5,1$ and $2 \mathrm{rpm}$ were shown in Fig. 7. As already noted, these temperatures relate to the temperatures in the anvils connected to the disks and the values were recorded at a distance of 
$10 \mathrm{~mm}$ from the disk surfaces. This means in practice that the true temperatures of the disks are higher than these measured values. Nevertheless, the results show clearly the effect of the rotation rate on the temperature increment during HPT processing with higher temperatures recorded at the faster rates. These results, and the effect of the rotation rate, are consistent with earlier values of the temperature rises measured experimentally for disks of $\mathrm{Al}, \mathrm{Cu}$ and Fe in HPT processing [35].

A recent report examined the temperature rise in HPT processing with specific reference to the heat generated in $\mathrm{CP}$ Ti of grade 2 [36]. Using a combination of direct measurements of the temperature rise and finite element modeling, it was shown that the rise in temperature, $\Delta T$, may be represented by a relationship of the form [36]:

$\Delta T=0.22 \sigma w[1+1.28(1-\exp (-t / 482))]$

where $\sigma$ is the flow stress of the metal which was taken from Table 1 for $N=10$ turns at different rotation rates, $w$ is the rotation rate equal to $0.052,0.105$ and $0.210 \mathrm{rad} \mathrm{s}^{-1}$ for rotation speeds of $0.5,1$ and $2 \mathrm{rpm}$, respectively, and $t$ is the total rotation time in units of seconds. Using eq. (2), it is estimated that the rise in the sample temperature after HPT for rotation speeds of $0.5,1$ and $2 \mathrm{rpm}$ is of the order of $\sim 25, \sim 42$ and $\sim 68 \mathrm{~K}$, respectively. Therefore, CP-Ti deformed at room temperature $(296 \mathrm{~K})$ may reach temperatures of $\sim 320$, $\sim 340$ and $\sim 370 \mathrm{~K}$ for rotation speeds of $0.5,1$ and $2 \mathrm{rpm}$, respectively.

Based on the DSC measurements in Fig. 5, these increases in temperature may not be sufficient to prevent an $\alpha$ to $\omega$-phase transformation. Nevertheless, the imposition of high rotation rates, when combined with the potential for plastic localization and some adiabatic shearing, is probably sufficient to prevent a stabilization of the $\omega$ phase during HPT. Furthermore, the low heat conductivity of $\mathrm{Ti}$ may also enhance the localization of plastic flow.

\subsection{Effect of rotation speed on the phase transformation}


The present study demonstrates that the rotation speed is an important factor in characterizing the occurrence of the $\alpha$ to $\omega$-phase transformation during HPT processing. It is important to note that increasing the applied pressure or the processing of higher purity $\mathrm{Ti}$ may promote the $\alpha$ to $\omega$-phase transformation even at high rotation speeds.

To provide a direct comparison with published data, Table 2 summarizes the results reported for various effective parameters on the $\alpha$ to $\omega$ phase transformation used in the HPT processing of Ti where the columns represent the applied pressure, $P$, the numbers of turns, $N$, the rotation speed, $w$, the oxygen content, the volume fraction of the $\omega$-phase expressed as a percentage and the appropriate reference. These results and the present investigation show clearly the effect of each parameter on the formation of the $\omega$-phase in Ti. The volume fraction of $\omega$-phase decreased by increasing the oxygen content at a constant $P, N$ and $w$ [7]. The fraction of the $\omega$-phase increased both with increasing pressure and with increasing the numbers of rotations [8]. The results show that $80 \% \omega$-phase was reported after 10 turns of HPT processing in high purity (99.9\%) Ti using a pressure of $6.0 \mathrm{GPa}$ pressure and a rotation rate of $1 \mathrm{rpm}$ [10] and 100\% $\omega$-phase was reported after 20 turns of HPT processing in the same high purity $\mathrm{Ti}$ with a pressure of $5.0 \mathrm{GPa}$ and a rotation rate of $0.2 \mathrm{rpm}$ [12]. Conversely, an $\omega$-phase was not detected by XRD in a Ti having a relatively high oxygen content after processing at $6.0 \mathrm{GPa}$ [18]. Finally, the present investigation demonstrates that the fraction of $\omega$-phase decreased by increasing the rotation speed.

\section{Summary and conclusions}

1. Different rotation speeds of $0.5,1$ and $2 \mathrm{rpm}$ were applied for the HPT processing of a grade 2 commercial purity titanium under $5.0 \mathrm{GPa}$ up to 10 turns. An $\alpha$ to $\omega$-phase transformation occurred during HPT at different rotation speeds but the volume fraction of the $\omega$-phase decreased when the rotation speed was increased. The results show that the 
hardness and strength are decreased by processing the specimens at higher rotation rates.

2. Heat generation during HPT processing is the main contributor preventing the formation of the $\omega$-phase at higher rotation speeds. The difficulty in $\omega$-phase formation is assisted by the low stability of the $\omega$-phase at relatively low temperatures (377-470 K).

3. The rotation speed is an important factor in characterizing the occurrence of the $\alpha$ to $\omega$-phase transformation during HPT processing. The stabilization of the $\omega$ phase is prevented during HPT at high rotation speeds due to plastic localization and adiabatic shearing that produces local heating.

\section{Acknowledgements}

The authors thank Southampton Nanofabrication Center for assistance in TEM sample preparation using FIB. This work was supported by the European Research Council under Grant Agreement No. 267464-SPDMETALS.

\section{References}

1. S.K. Sikka, Y.K. Vohra, R. Chidambaram, Prog. Mater. Sci. 27 (1982) 245-310.

2. Y.K. Vohra, P.T. Spencer, Phys. Rev. Lett. 86(14) (2001) 3068-3071.

3. Y. Akahama, H. Kawamura, T.L. Bihan, Phys. Rev. Lett. 87 (2001) 275503.

4. R. Ahuja, J.M. Wills, B. Johansson, O. Eriksson, Phys. Rev. B 48 (1993) 16269-16279.

5. J.C. Jamieson, Science 140 (1963) 72-73.

6. A.R. Kilmametov, A.V. Khristoforov, G. Wilde, R.Z. Valiev, Z. Krist. Suppl. 26 (2007) $339-44$.

7. Y. Todaka, J. Sasaki, T. Moto, M. Umemoto, Scr. Mater. 59 (2008) 615-618.

8. Y. Ivanisenko, A. Kilmametov, H. Rösner, R.Z. Valiev, Int. J. Mater. Res. 99 (2008) 3641.

9. K. Edalati, E. Matsubara, Z. Horita, Metall. Mater. Trans. A 40 (2009) 2079-2089. 
10. K. Edalati, T. Daio, M. Arita, S. Lee, Z. Horita, A. Togo, I. Tanaka, Acta Mater. 68 (2014) 207-213.

11. M. Shirooyeh, J. Xu, T.G.Langdon, Mater. Sci. Eng. A 614 (2014) 223-231.

12. N. Adachi, Y. Todaka, H. Suzuki, M. Umemoto, IOP Conf. Series: Mater. Sci. Eng. 82 (2015) 012020.

13. R.Z. Valiev, R.K. Islamgaliev, I.V. Alexandrov, Prog. Mater. Sci. 45 (2000) 103.

14. T.G. Langdon, Acta Mater. 61 (2013)7035-7059.

15. A.P. Zhilyaev, T.G. Langdon, Prog. Mater. Sci. 53 (2008) 893-979.

16. R.E. Bolmaro, V.L. Sordi, M. Ferrante, H-G. Brokmeier, M. Kawasaki, T.G. Langdon, IOP Conf. Series: Mater. Sci. Eng. 63 (2014) 012147.

17. R.G. Hennig, D.R. Trinkle, J. Bouchet, S.G. Srinivasan, R.C. Albers, J.W. Wilkins, Nature Mater. 4 (2005) 129-133.

18. C.T. Wang, A.G. Fox, T.G. Langdon, J. Mater. Sci. 49 (2014) 6558-6564.

19. R.B. Figueiredo, P.R. Cetlin, T.G. Langdon, Mater. Sci. Eng. A 528 (2011) 8198-8204.

20. R.B. Figueiredo, P.H.R. Pereira, M.T.P. Aguilar, P.R. Cetlin, T.G. Langdon, Acta Mater. 60 (2012) 3190-3198.

21. M. Kai, Z. Horita, T.G. Langdon, Mater. Sci. Eng. A 488 (2008) 117-124.

22. Cullity BD, Stock SR. Elements of X-ray Diffraction. 3rd Ed, Englewood Cliffs, Prentice Hall, NJ, U.S.A. 2001.

23. J. Wang J, Z. Horita, M. Furukawa, M. Nemoto, N.K. Tsenev, R.Z. Valiev, Y. Ma, T.G. Langdon, J. Mater. Res. 8 (1993) 2810-2818.

24. M. Furukawa, Z. Horita, M. Nemoto, R.Z. Valiev, T.G. Langdon, Size. Acta Mater. 44 (1996) 4619-4629.

25. C. Xu, M. Furukawa, Z. Horita, T. G. Langdon, Mater. Sci. Eng. A398 (2005) 66-76.

26. C. Xu, K. Xia, T. G. Langdon, Acta Mater. 55 (2007) 2351-2360. 
27. C. Xu, Z. Horita, T. G. Langdon, Acta Mater. 55 (2007) 203-212.

28. R.Z. Valieva, I.V. Alexandrov, Y.T. Zhu, T.C. Lowe, J. Mater. Res. 17 (2002) 5-8.

29. P. Kumar, M. Kawasaki, T.G. Langdon, J. Mater. Sci. 51 (2016) 7-18.

30. A.V. Sergueeva, V.V. Stolyarov, R.Z. Valiev, A.K. Mukherjee, Scr. Mater. 45 (2001)

$747-752$

31. N. Adachi, Y. Todaka, H. Suzuki, M. Umemoto, Scr. Mater. 98 (2015) 1-4.

32. W.F. Hosford, R.M. Caddell, Metal Forming Mechanics and Metallurgy, third ed., Cambridge University Press, New York, NY, 2007.

33. A.P. Zhilyaev, J.M. García-Infanta, F. Carreño, T.G. Langdon, O.A. Ruano, Scr. Mater. 57 (2007) 763-765.

34. S. Hóbor, Z. Kovács, Á. Révész, J. Alloys Compd 495 (2010) 352-355.

35. K. Edalati, R. Miresmaeili, Z. Horita, H. Kanayama, R. Pippan, Mater. Sci. Eng. A 528 (2011) 7301-7305.

36. P.H.R. Pereira, R.B. Figueiredo, Y. Huang, P.R. Cetlin, T.G. Langdon, Mater. Sci. Eng. A593 (2014)185-188.

\section{Tables captions}

Table 1. The mechanical properties and $\omega$-phase volume fractions of CP-Ti after HPT processing under different conditions.

Table 2. Summary of experimental parameters used to investigate Ti processed by HPT $[7,8$, $10,12,16,18]$.

\section{Figures captions}

Fig. 1. (a) X-ray patterns near the edge after 10 turns and different rotation rates and (b) values of the Vickers microhardness: the lower dashed line shows the fully-annealed initial condition.

Fig. 2. TEM image and corresponding SAED pattern for Ti after 10 turns of HPT processing 
at $0.5 \mathrm{rpm}$. Some reflections of the $\omega$ and $\alpha$ phases are indicated.

Fig. 3. (a) X-ray patterns near the edge and (b) values of the Vickers microhardness measured across disks processed from 1 to 10 turns at a rotation speed of $0.5 \mathrm{rpm}$ : the lower dashed line shows the fully-annealed initial condition.

Fig. 4. Stress-strain curves at an initial strain rate of $1.0 \times 10-3 \mathrm{~s}^{-1}$ in (a) the initial annealed condition and aftre10 turns of HPT at different rates and (b) after HPT for various numbers of turns at a rotation rate of $0.5 \mathrm{rpm}$.

Fig. 5. Non-Isothermal (scanning) DSC measurements of Ti after 10 turns of HPT processing at a rotation rate of $0.5 \mathrm{rpm}$ : the heating rate is $\sim 10 \mathrm{~K} \mathrm{~min}^{-1}$.

Fig. 6. (a) X-ray patterns near the edge and (b) values of the Vickers microhardness for disks processed by 10 turns at $0.5 \mathrm{rpm}$ and either measured after HPT processing or measured after additional annealing for $15 \mathrm{~min}$ at 423 or $473 \mathrm{~K}$.

Fig. 7. Temperature evolution as a function of time using experimental results for $\mathrm{Ti}$ processed by HPT through 10 turns at different rotation speeds. 
Table 1. The mechanical properties and $\omega$-phase volume fractions of CP-Ti after HPT processing under different conditions.

\begin{tabular}{cccccc}
\hline $\begin{array}{c}\text { Rotation } \\
\text { rate }(\mathrm{rpm})\end{array}$ & $\begin{array}{c}\text { Numbers of } \\
\text { rotations }\end{array}$ & $\mathrm{Hv}$ & $\begin{array}{c}\mathrm{UTS} \\
(\mathrm{MPa})\end{array}$ & $\delta(\%)$ & $\omega(\%)$ \\
\hline- & 0 & $170 \pm 3$ & 450 & 53 & 0 \\
\hline 0.5 & 1 & $307 \pm 7$ & 900 & 27 & $\sim 5$ \\
& 10 & $368 \pm 11$ & 1000 & 3 & $\sim 65$ \\
\hline 1 & 10 & $300 \pm 5$ & 950 & 9 & $\sim 27$ \\
\hline 2 & 10 & $293 \pm 7$ & 930 & 26 & $\sim 12$ \\
\hline
\end{tabular}


Table 2. Summary of experimental parameters used to investigate Ti processed by HPT $[7,8$, $10,12,16,18]$.

\begin{tabular}{|c|c|c|c|c|c|}
\hline $\mathrm{P}(\mathrm{GPa})$ & $\mathrm{N}$ & $\begin{array}{c}w \\
(\mathrm{rpm})\end{array}$ & $\begin{array}{l}\text { Oxygen content } \\
(\%)\end{array}$ & $\omega(\%)$ & Ref. \\
\hline 5 & 10 & 0.2 & 0.05 & $\sim 90$ & Todaka et al. [7] \\
\hline 5 & 10 & 0.2 & 0.12 & $\sim 80$ & \\
\hline 4 & 5 & 1 & - & $\sim 25$ & Ivanisenko et al. [8] \\
\hline 5 & 5 & 1 & & $\sim 55$ & \\
\hline 6 & 5 & 1 & & $\sim 70$ & \\
\hline 6 & 10 & 1 & & $\sim 90$ & \\
\hline 6 & 10 & 1 & $<0.1$ & $\sim 80$ & Edalati et al. [10] \\
\hline 5 & 20 & 0.2 & $<0.1$ & $\sim 100$ & Adachi et al. [12] \\
\hline 6 & 5 & 1 & $0.25^{(\max )}$ & $\sim 50$ & Bolmaro et al. [16] \\
\hline 6 & 10 & 1 & $0.25^{(\max )}$ & 0 & Wang et al. [18] \\
\hline 5 & 10 & 0.5 & $0.25^{(\max )}$ & $\sim 65$ & This investigation \\
\hline 5 & 5 & 0.5 & & $\sim 60$ & \\
\hline 5 & 10 & 1 & & $\sim 27$ & \\
\hline 5 & 10 & 2 & & $\sim 12$ & \\
\hline
\end{tabular}




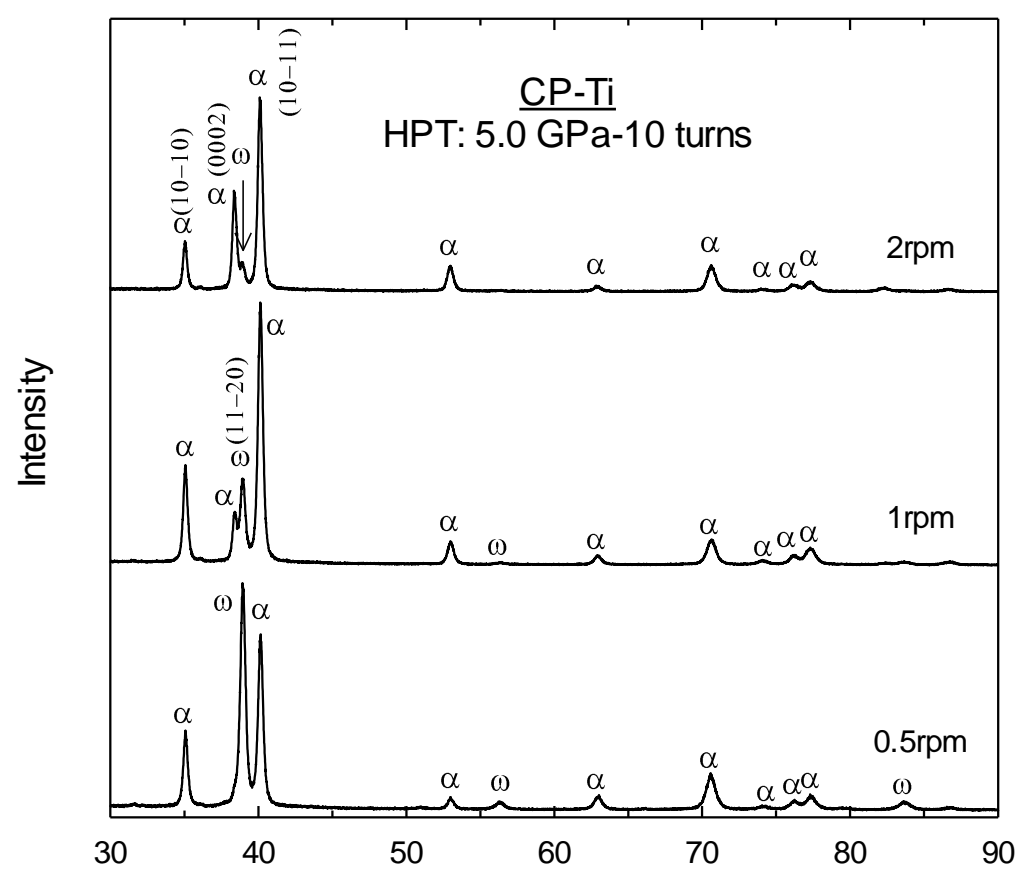

a)

2-Theta

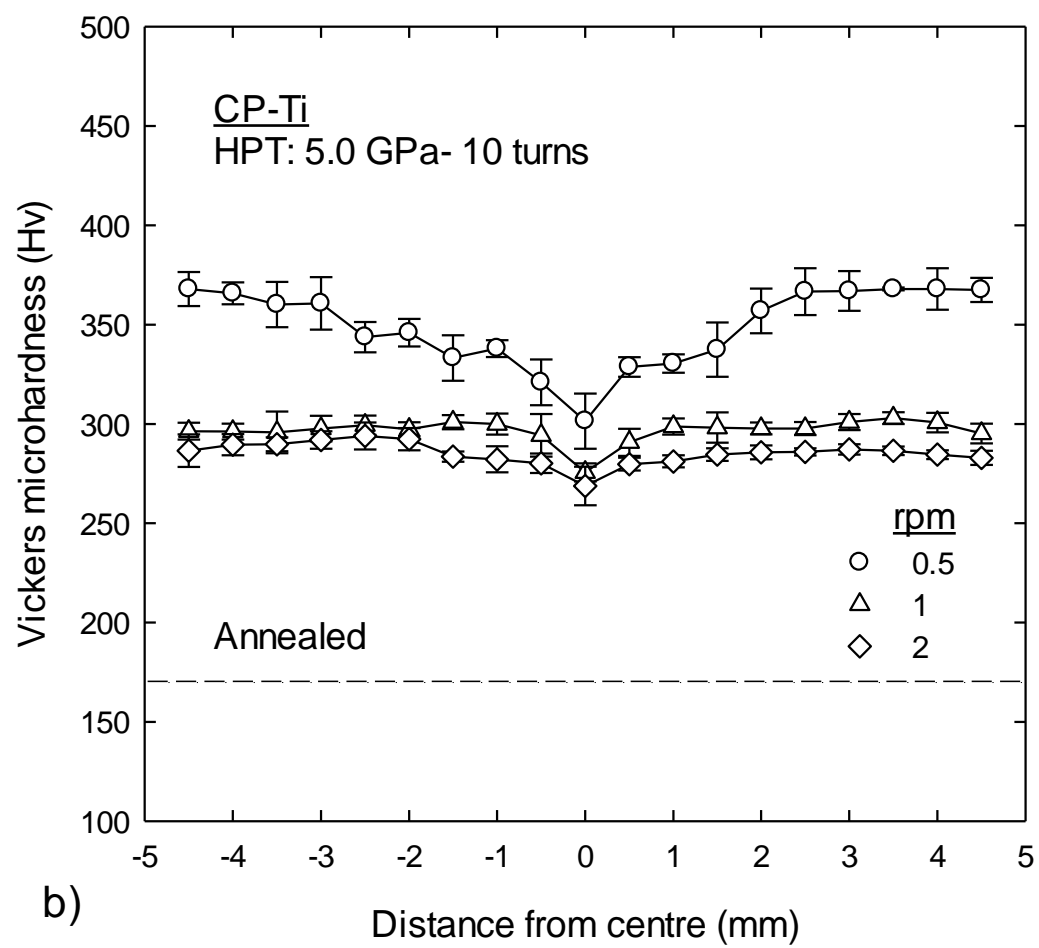

Fig. 1. (a) X-ray patterns near the edge after 10 turns and different rotation rates and (b) values of the Vickers microhardness: the lower dashed line shows the fully-annealed initial condition. 


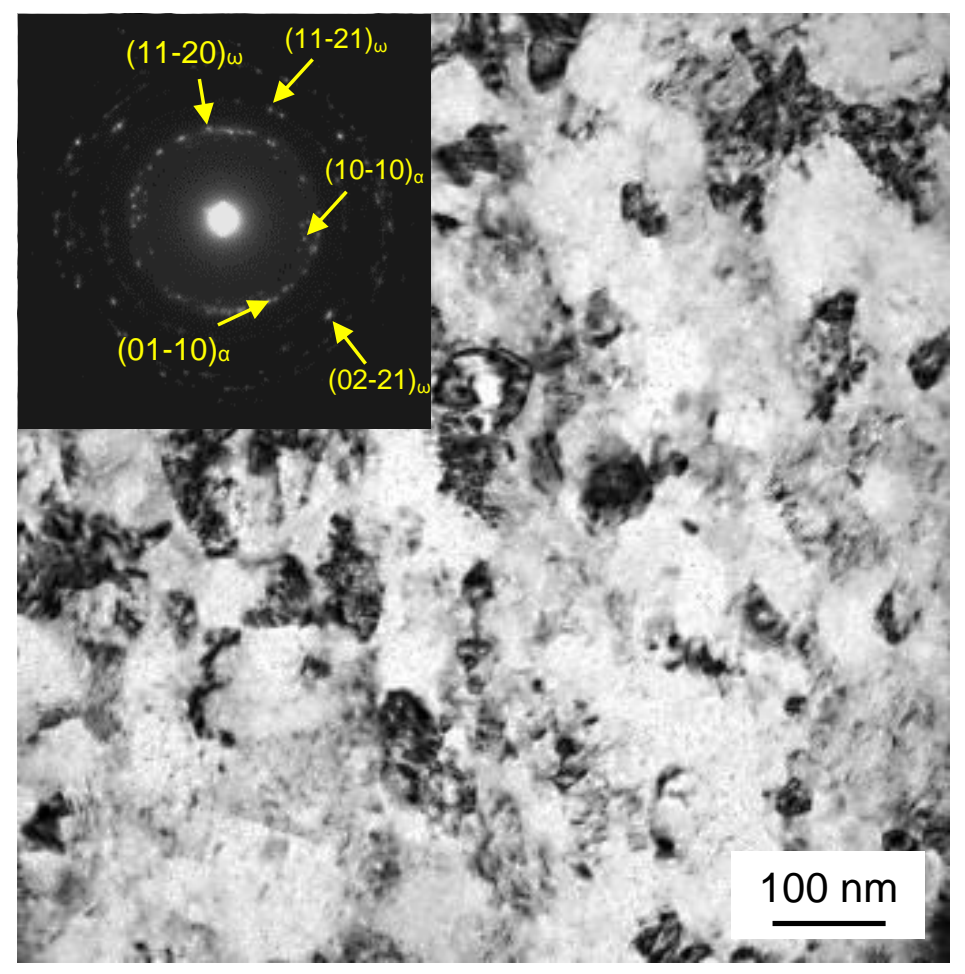

Fig. 2. TEM image and corresponding SAED pattern for Ti after 10 turns of HPT processing at $0.5 \mathrm{rpm}$. Some reflections of the $\omega$ and $\alpha$ phases are indicated. 


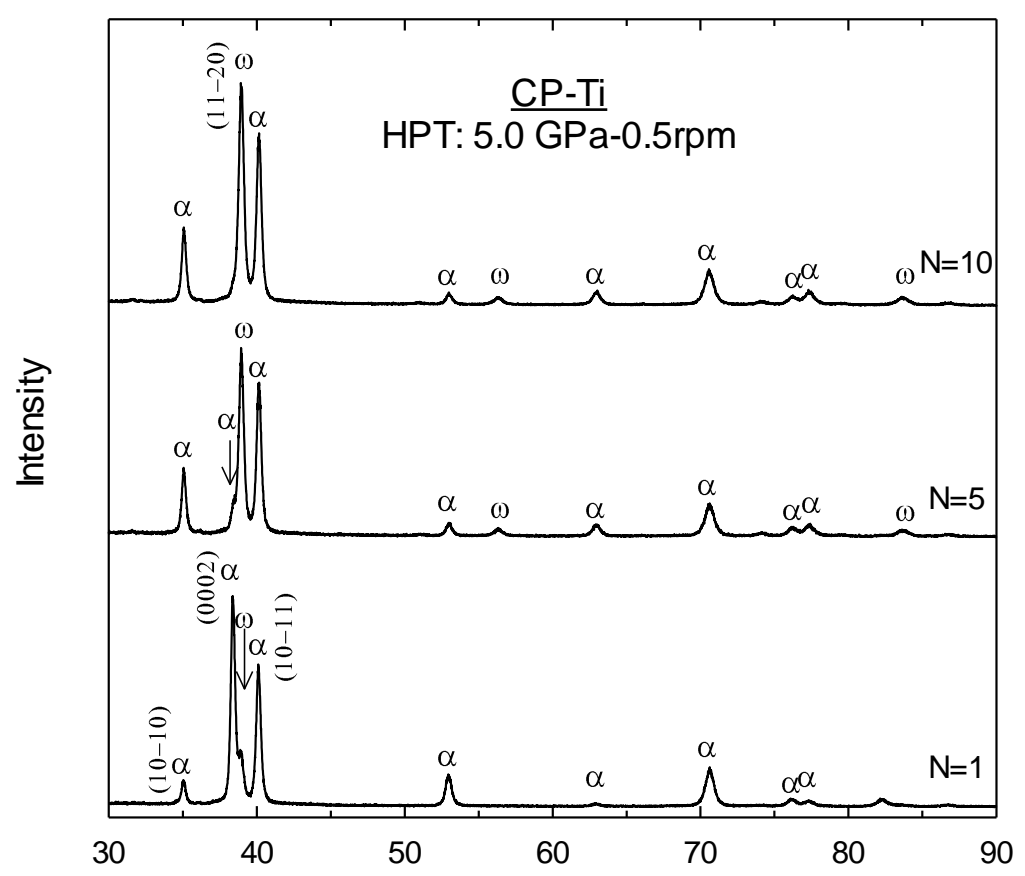

a)

2-Theta

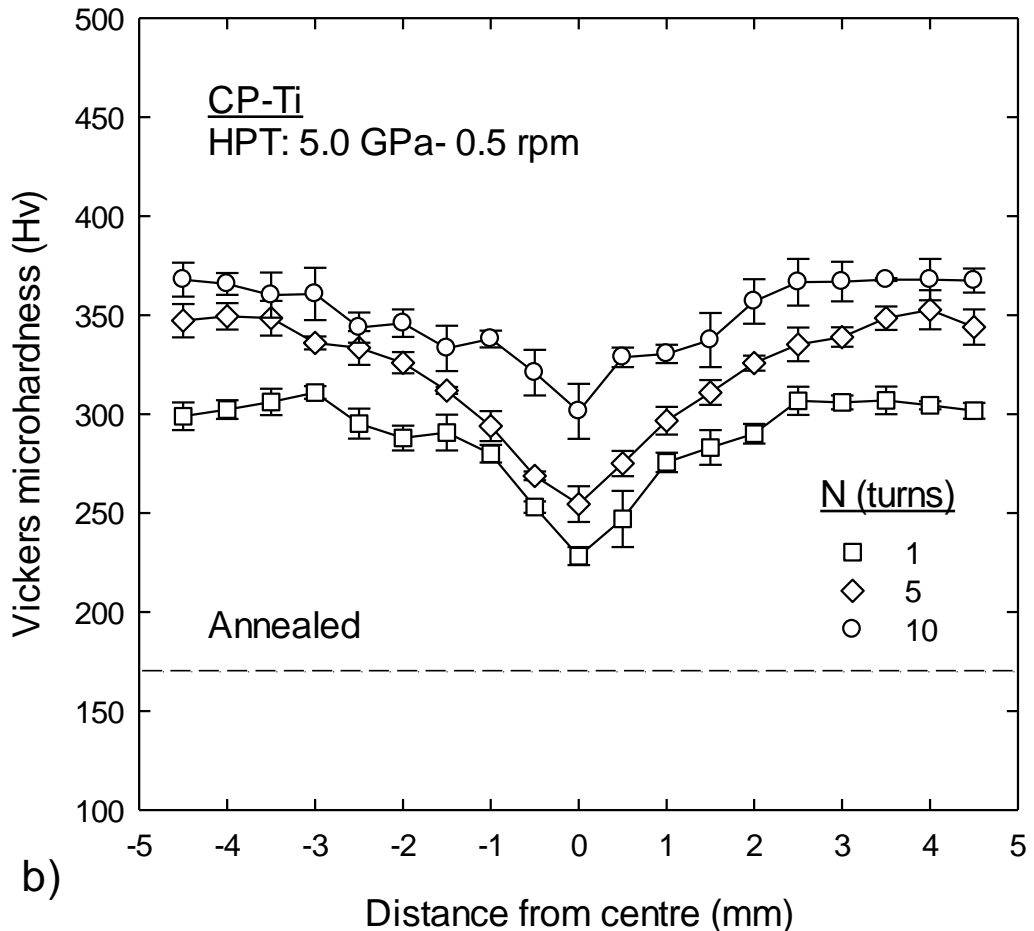

Fig. 3. (a) X-ray patterns near the edge and (b) values of the Vickers microhardness measured across disks processed from 1 to 10 turns at a rotation speed of $0.5 \mathrm{rpm}$ : the lower dashed line shows the fully-annealed initial condition. 

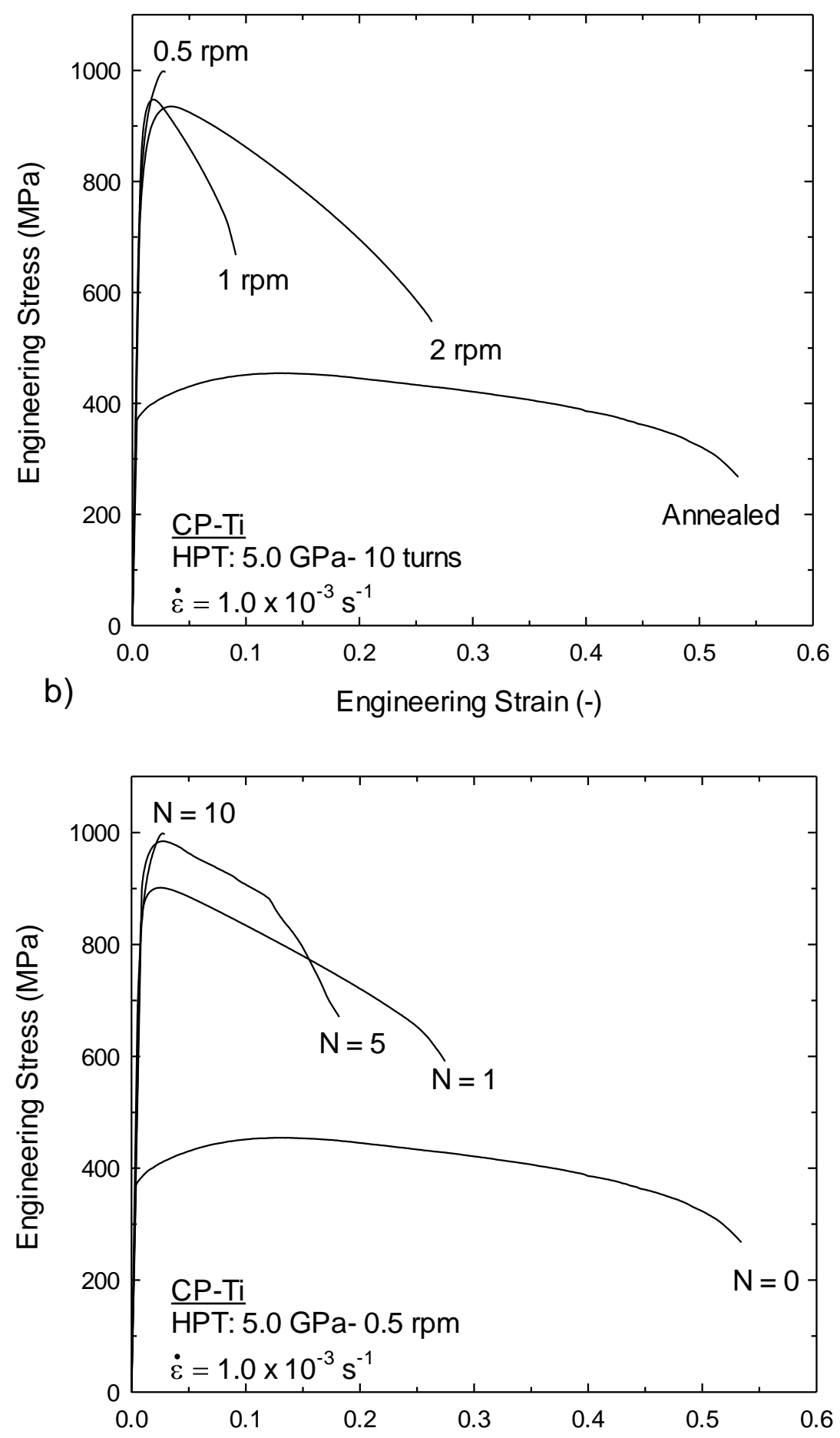

a)

Engineering Strain (-)

Fig. 4. Stress-strain curves at an initial strain rate of $1.0 \times 10-3 \mathrm{~s}^{-1}$ in (a) the initial annealed condition and aftre10 turns of HPT at different rates and (b) after HPT for various numbers of turns at a rotation rate of 0.5 . 


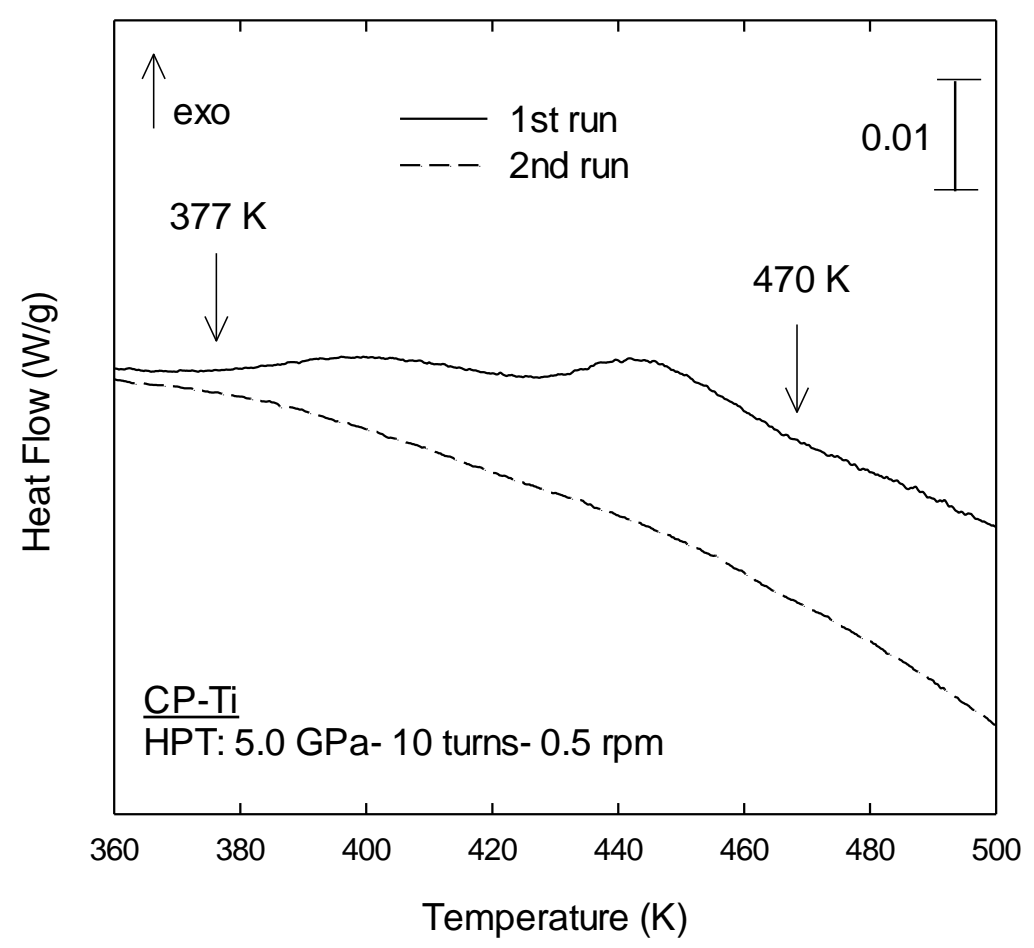

Fig. 5. Non-Isothermal (scanning) DSC measurement of Ti after 10 turns HPT processing at a rotation rate of $0.5 \mathrm{rpm}$ : the heating rate is $10 \mathrm{~K} \mathrm{~min}^{-1}$. 


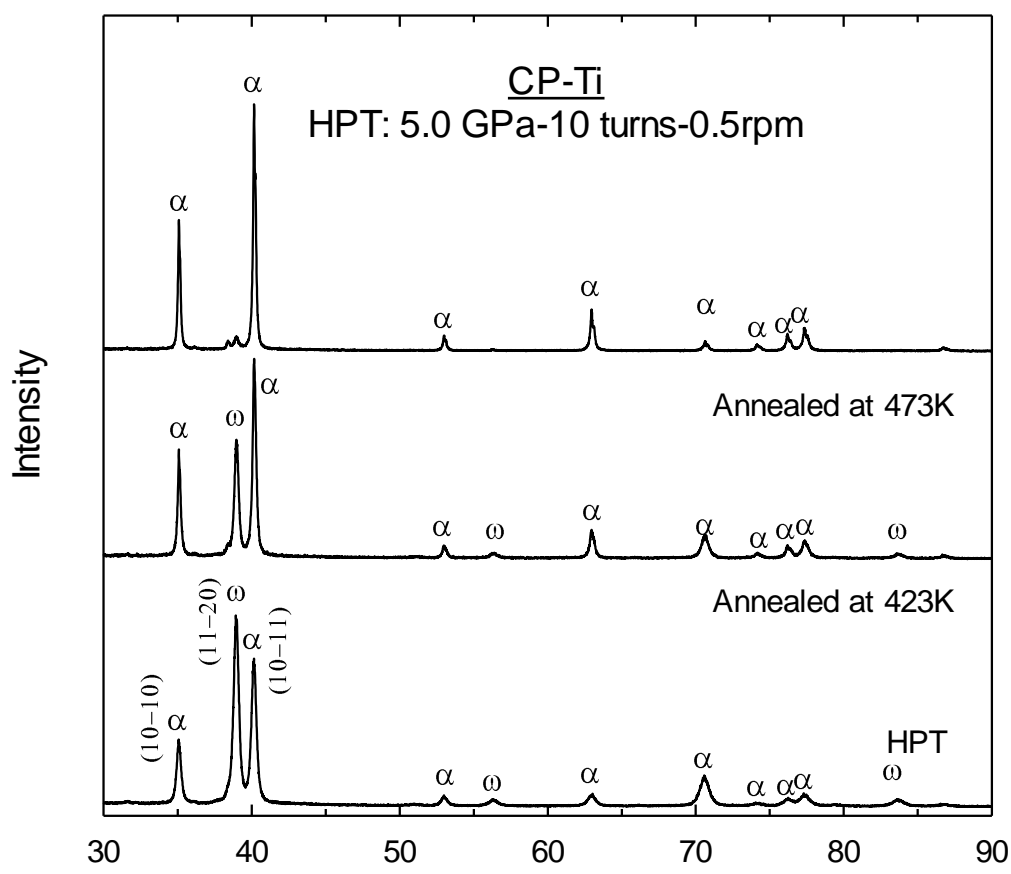

a)

2-Theta

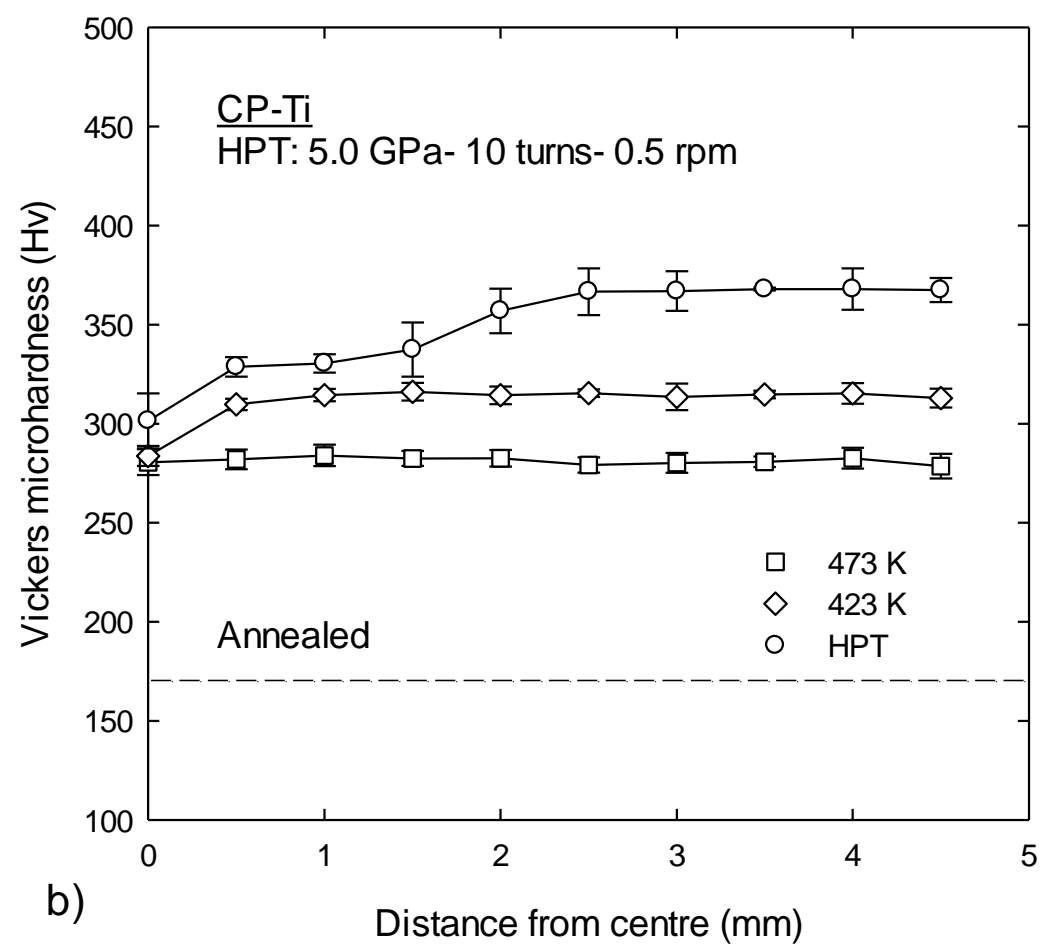

Fig. 6. (a) X-ray patterns near the edge and (b) values of the Vickers microhardness for disks processed by 10 turns at $0.5 \mathrm{rpm}$ and either measured after HPT processing or measured after additional annealing for $15 \mathrm{~min}$ at 423 or $473 \mathrm{~K}$. 


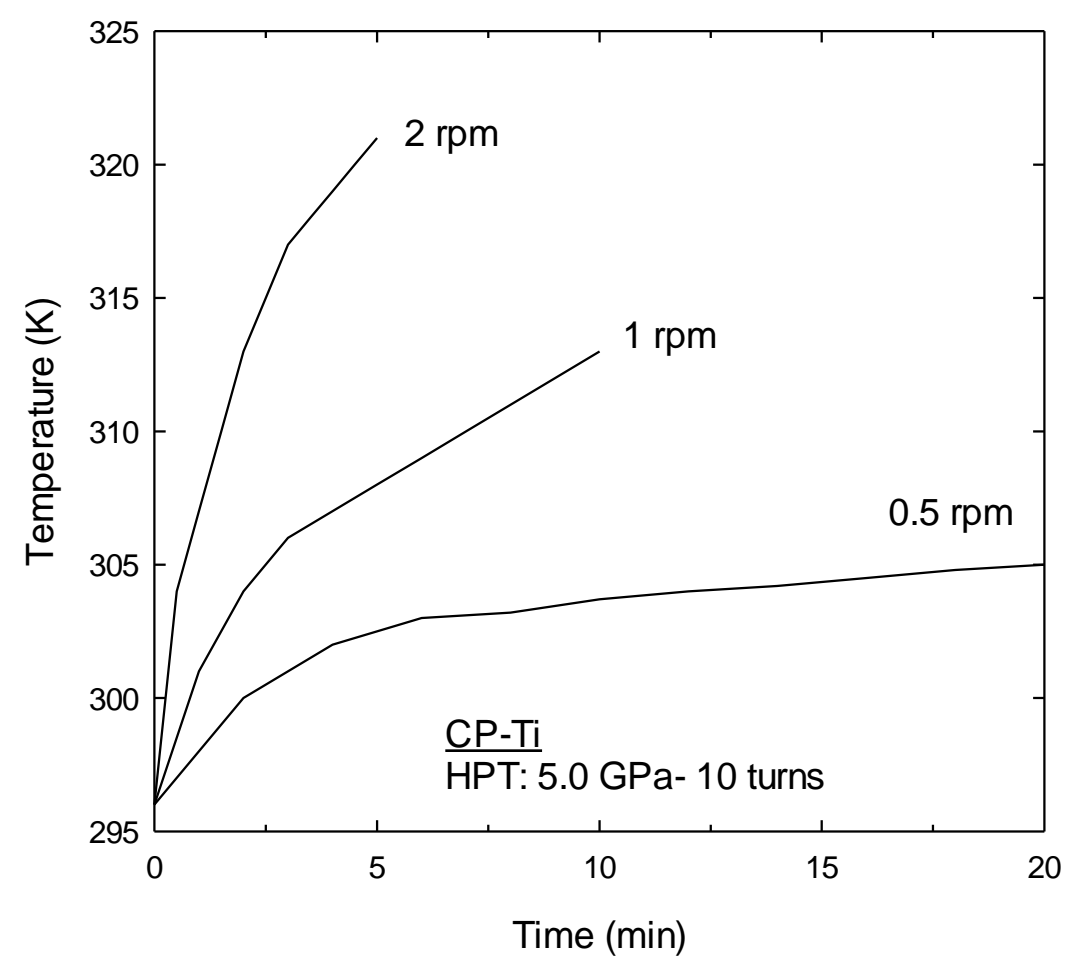

Fig. 7. Temperature evolution as a function of time using experimental results for $\mathrm{Ti}$ processed by HPT through 10 turns at different rotation speeds. 